\title{
SUCCESSFUL REMOVAL OF A MYXOMA OF THE LEFT ATRIUM
}

\author{
BY \\ J. LEIGH COLLIS AND N. J. SHAH \\ From Queen Elizabeth Hospital, Birmingham
}

(RECEIVED FOR PUBLICATION MARCH 19, 1959)

In view of the obstruction at the mitral valve produced by myxoma of the left atrium it is not surprising that this condition is confused with mitral stenosis. It is further to be expected that even an uncommon condition such as this will be encountered in many centres because of the frequency of the surgical treatment of mitral stenosis. This is borne out by the number of recent reports (Crafoord, 1955 ; Bigelow, Dolan, and Campbell, 1956; Scannell, Brewster, and Bland, 1956 ; Brock, 1956 ; Chin and Ross, 1957 ; Van Buchem and Eerland, 1957 ; Belcher, 1958 ; Fatti and Reid, 1958). A further case is reported here because it demonstrates the difficulties in diagnosis and the method used in its treatment proved simple and effective.

The physical characteristics, the histology, the symptoms, the physical signs, and the methods of pre-operative diagnosis have been discussed by many writers (Straus and Merliss, 1945 ; Mahaim, 1945; Brewin, 1948, 1951; Mills and Philpott, 1951 ; Goldberg, Glenn, Dotter, and Steinberg, 1952; Goldberg and Steinberg, 1955; Likoff, Geckeler, and Gregory, 1954), and the literature has been reviewed by Fatti and Reid (1958) and it is not proposed to discuss it here.

In view of the ever-present possibility of encountering this tumour during mitral valvotomy we had worked out a plan to deal with the situation. In spite of the friable nature of the tumour we felt that it would be less hazardous to close the incision and operate again at a later date. Our original intention was to approach the tumour via the right atrium and the interatrial septum as suggested by Brock (1956) and as used successfully by Chin and Ross (1957) and by Belcher (1958). In both these cases the tumour broke during removal and had to be sucked out piecemeal. In order to avoid the risk of possible fragmentation of the tumour we devised an instrument (Fig. 1) which would enclose the tumour during its removal. The centre of a dessert spoon was cut out and a flexible wire mesh bag was soldered to the lower margin of the rim that was left. The tip of the spoon was $\vec{\infty}$ sharpened so that it could be used for cutting the $\mathbb{D}$ pedicle. The approach via the right atrium was $\underset{\mathbb{D}}{\mathbb{D}}$ practised in the post-mortem room. We found 3 it difficult to place the incision in the interatrial Ф septum so as to avoid cutting into the tumour. $\overrightarrow{0}$ Furthermore, in the case of a large tumour, this of incision cannot be extended without serious risk (Chin and Ross, 1957).

We discussed this problem with Mr. A. L. d'Abreu, who very kindly called to our attention a report by Scannell and his colleagues of the

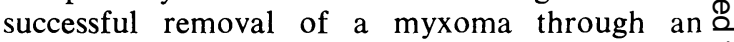
incision in the left atrium, and as Mr. d'Abreu $\vec{\circ}$ had been present at this operation he was able to 3 supplement this report with many practical and helpful suggestions.

Air embolus of the coronary arteries is a possible hazard in the approach through the left atrium. However, during aortic valvotomy $\tilde{x}$ carried out by the aortic approach we had noticed that this complication had not a sen and we felt $\stackrel{3}{\text {. }}$. that this was due to the absence of any positive pressure in the aorta when this vessel is laid open. Such an opening would also allow any air, blood 의 clot, or tumour fragment to escape before the $D$ systemic circulation was restored. We therefore decided to make a small incision in the aorta just $N$ before opening the left atrium.

Dissections of the heart were made in order to $\tilde{O}^{\circ}$ see if an adequate exposure could be obtained through the left atrium. It was found that this was possible provided the pericardium was clearedo well back so that the left pulmonary veins were $\frac{\varnothing}{\varnothing}$ laid bare. By starting an incision below the $\stackrel{\oplus}{+}$ inferior pulmonary vein or between the two veins 0 it was possible to obtain room for an incision 30 to 4 in. long in the atrial wall.

A revised plan was now made to perform $\mathbb{\otimes}$ the second operation under hypothermia witho 


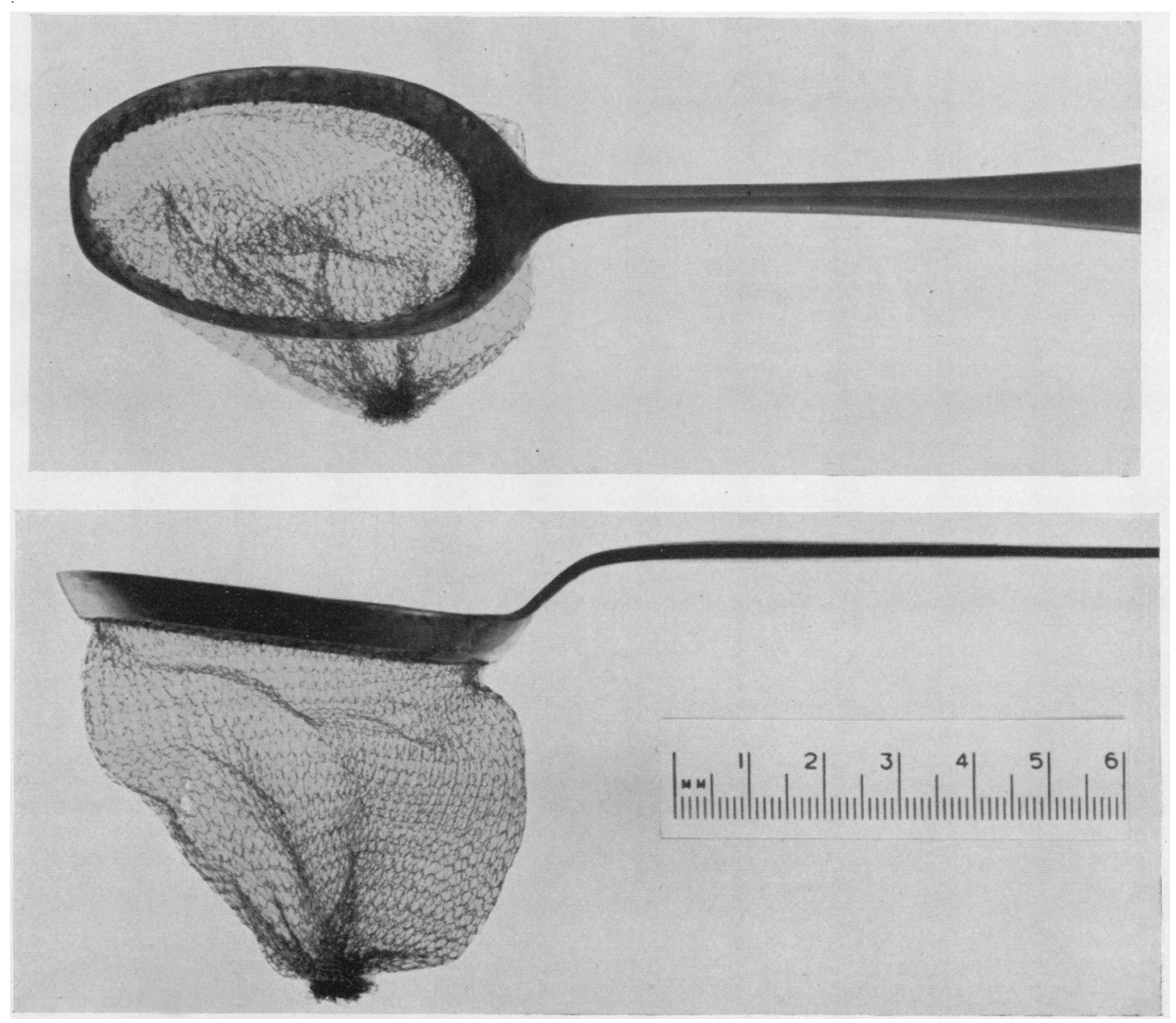

FIG. 1.-Two views of the instrument used for removing the tumour are shown.

circulatory arrest and to remove the tumour via the left atrium. The growth was to be collected with the special cutting spoon and wire net. Lastly, greater safety from a coronary air embolism was to be given by having a separate incision in the aorta.

\section{CASE RePort}

Mrs. E. L., aged 38, was seen in January, 1957, complaining of shortness of breath following an attack of bronchitis six weeks previously. There was no previous history of rheumatic fever or chorea. Physical examination showed that she was well nourished. The pulse was regular, the jugular venous pressure was not raised, the liver was not palpable, and there was no oedema of the ankles.

Physical Signs.-The first heart sound was accentuated, and a mid-diastolic and soft systolic murmur were present. There was no opening snap. The pulmonary second sound was accentuated but was not reduplicated. Radiological screening showed enlargement of the left atrium and of the right ventricle. The E.C.G. showed bifid $P$ waves, but no axis deviation or ventricular preponderance. A diagnosis of tight mitral stenosis with a minor degree of incompetence was made and operation was advised but refused.

Over the next 15 months the patient's symptoms became worse and finally she was admitted to hospital in May, 1958. Physical examination at this time showed that the diastolic murmur at the apex could not be heard any longer, but the systolic murmur was still present.

First OPERATION.-On June 7 a left anterolateral thoracotomy was carried out and the mitral valve explored through the left atrial appendage. Immediately the finger encountered a tumour of firm consistency which was found to be rising from the interatrial septum and to be projecting over the mitral valve without actually obstructing it. The valve felt normal. Following our plan we decided to close the 
incision and to operate again later. The atrial appendage was amputated in order to minimize the risk of clot formation. On the third post-operative day the patient was started on a colirse of anticoagulants ("dindevan") and this treatment was maintained until two days before the second operation. There were no post-operative complications.

SeCond OPERATION.-On July 5 the patient was anaesthetized and cooled in a bath (Sellick, 1957) down to $31.5^{\circ} \mathrm{C}$. She was placed in a supine position on the operating table over a rewarming blanket. Both arms were extended. The table was rotated to bring the left side up to $20^{\circ}$. The previous incision was reopened and extended across the midline to the right posterior axillary fold. The pericardium was found to be lightly adherent and was dissected off the heart easily. The pericardium was opened widely and special care was taken to carry the dissection well back between the two left pulmonary veins. Rubber slings were then placed round the superior and inferior venae cavae and round the superior and inferior left pulmonary veins. Retraction on the last two slings increased the area of the left atrium available for incision. Separate cross clamps were placed across the pulmonary artery and the aorta but were not closed. Two stay sutures were inserted into the aorta proximal to the clamp. The circulation was arrested by tightening the caval slings and after a few heart beats the pulmonary and aortic cross clamps were closed. A $\frac{3}{4}$ in. incision was made in the aorta between the stay sutures. The left atrium was incised just above the site of the amputated appendage and the incision was extended backwards below the inferior pulmonary vein. Through this wide opening the spoon with its attached wire mesh bag was inserted in such a way that the tumour rested in the bag. With the sharp end of the spoon the pedicle was divided and the whole tumour removed in one piece. The site of the pedicle was then examined and found to be smooth. Because of the curve of the atrium the incision could not be closed with a clamp. Therefore the posterior half of the incision was closed with interrupted sutures, the cavity of the atrium was filled with saline, and a clamp placed across the rest of the incision. The caval slings were then released and the pulmonary artery clamp was removed. As the blood welled out of the aortic incision some air and a large blood clot came away. The aortic incision was closed with a clamp, and the aortic cross clamp removed. The total time of circulatory arrest was seven and a half minutes. The remainder of the atrial incision was sutured and the aortic incision closed with continuous atraumatic silk suture. At this stage atrial fibrillation began and the ventricular action was poor. Manual cardiac massage was started with improvement in the left ventricular beat, but the right ventricle remained dilated and cyanosed. Adrenaline was injected into the right ventricle, but after a few strong beats ventricular fibrillation supervened. Electrical defibrillation was carried out, but a normal beat could not be maintained. A cardiac

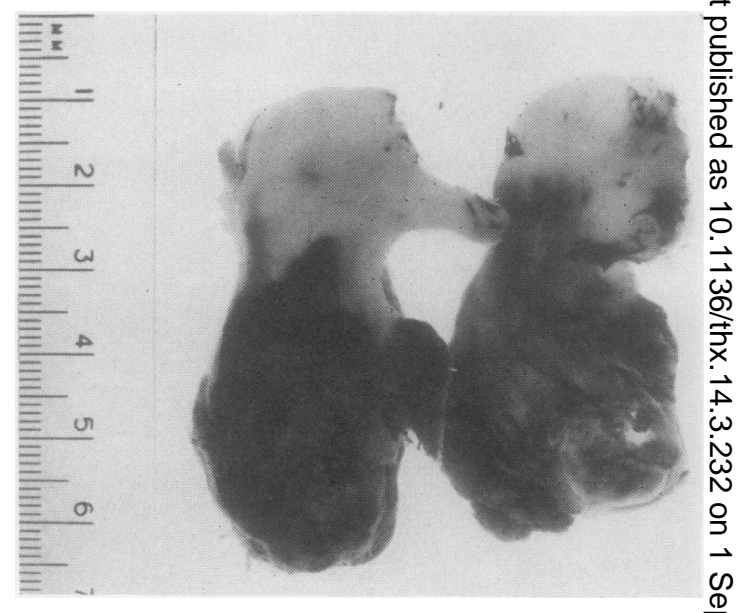

Fig. 2.-The myxoma from the left atrium was halved, and the two halves are shown. On the left is the cut surface, the lower part of which is heavily stained with blood. This staining was not so extensive at the time of removal. On the right is the outer surface of the tumour and the flat circular area of the lower part ${ }^{-}$ is the pedicle.

pacemaker was applied. There was an immediate. improvement and both ventricles began to beat $\square$ normally. After about one minute the pacemaking was discontinued and the heart continued to beat normally. After the patient had been warmed up to $34^{\circ} \mathrm{C}$. the incision was closed. She became fully $\frac{\mathrm{Q}}{\mathrm{D}}$ conscious about four hours after the end of operation 2 and made steady progress. She was discharged home $\vec{\circ}$ on the twentieth post-operative day.

REPORT ON THE TUMOUR.-An oblong tumour (Fig. 2) measured $6 \mathrm{~cm}$. by $3 \mathrm{~cm}$. The proximal half of the tumour is dark red and the distal half translucent.

The tissue shows delicate or "strap-like" cells embedded in a mucinous matrix and separated by collagenous fibrous tissue. The appearances are those 3 of a myxoma of the atrium.

Present Condition.-The patient has been seen at regular intervals in the follow-up clinic. She was lasto seen on November 29, 1958. She has no dyspnoea on exertion and is leading a normal life. The physical signs in the heart have disappeared.

\section{SUMmarY}

A case of the successful removal of a myxoma $\mathbb{N}$ of the left atrium is described.

The ease of access through the left atrium is shown. An instrument which safeguards againsto the risk of accidental fragmentation and emaolism is described. The added aortic incision is? considered to have been of great benefit.

When one of these tumours is found unexpectedly it is thought best to close the wound and operate according to the proposed plan three $\stackrel{\mathbb{D}}{\Omega}$ weeks later. 
We should like to thank Mr. A. L. d'Abreu for his help in evolving the present method of approach ; Mr. Biffen, the curator of the Instrument Department of the Queen Elizabeth Hospital, for making the spoon for us; Mr. Dee, of the Photographic Department, for photographs of the spoon and of the specimen, and Messrs. Knitmesh Ltd., 36, Victoria Street, London, S.W.1, for very kindly supplying the flexible wire mesh.

\section{REFERENCES}

Belcher, J. R. (1958). Brit. J. Tuberc., 52, 62 .
Bigelow, W. G., Dolan, F. G., and Campbell, F. W. Cited by Scannell et al. (1956). New Engl. J. Med., 254, 601.
Brewin, T. B. (1948). Guy's Hosp. Rep., 97, 64

(1951). Ibid., 100, 278.

Brock, R. (1956). Ibid., 105, 382.

Chin, E. F., and Ross, D. N. (1957). Brit. med. J., 1, 1447.

Crafoord, C. (1955). In International Symposium on Cardiovascular Surgery [Henry Ford Hospital, Detroit], ed. C. R. Lam, p. 202. Saunders, Philadelphia.

Fatti, L., and Reid, F. P. (1958). Brit. med. J., 2, 531.

Goldberg, H. P., and Steinberg, I. (1955). Circulation, 11, 963. Glenn, F., Dotter, C. T., and Steinberg, I. (1952). Ibid. 6. 762 .

Likoff, W., Geckeler, G. D., and Gregory, J. E. (1954). Amer. Heart J., 47, 619.

Mahaim, I. (1945). Les Tumeurs et les Polypes du Coeur. Masson, Paris.

Mills, P., and Philpott, M. (1951). Brit. Heart J., 13, 115.

Scannell, J. G., Brewster, W. R., and Bland, E. F. (1956). New Engl.J. Med. 254,601.

Sellick, B. A. (1957). Lancet, $1,443$.

Straus, R., and Merliss, R. (1945). Arch. Path. (Chicago), 39, 74.

Van Buchem, F. S., and Eerland, L. D. (1957). Dis. Chest, 31, 61. 